\title{
ResearchArticle
}

\section{In vivo screening of turmeric (Curcuma longa L.) germplasm of different duration groups against rhizome rot caused by Pythium and Fusarium spp.}

\author{
M. Lakshmi Naga Nandini, C.H. Ruth and K. Gopal
}

\begin{abstract}
SUMMARY
Field screening studies were conducted over a period of one year i.e. 2016-2017 in augmented block design with 120 available germplasm lines of turmeric (Curcuma longa L.) at College of Horticulture, Anantharajupeta. These lines were screened against the rhizome rot caused by Pythium graminicolum and Fusarium solani under natural conditions. The severity of rhizome rot is ranged from 0.00 to 92.86 per cent irrespective cultures screened. Among the germplasm cultures screened, cultures like IC-319341, Tenali Kasturi, VK-23, GS, IC-420606, IC-033007, IC-211641, PTS-8, Vikici, Dhindigam, ACC-48, Sonia, NB-60, Kasturi in short duration group, Prathibha, Thodupuztha, KTS-9, Prasangali, ACC-79 in medium duration group and NH-1, Ranga, Salem, Salem-2, Wagon, PTS-12, CL-8, CL-9, CL-10, CL-3, CL-4 in long duration group were resistant to rhizome rot showed $0.0 \%$ diseases incidence. More disease incidence (susceptible reaction) of rhizome rot was observed in long duration group.
\end{abstract}

Key Words : Germplasm, Rhizome rot, Turmeric, Varieties, Screening, Resistant

How to cite this article : Nandini, M. Lakshmi Naga, Ruth, C.H. and Gopal, K. (2018). In vivo screening of turmeric (Curcuma longa L.) germplasm of different duration groups against rhizome rot caused by Pythium and Fusarium spp. Internat. J. Plant Sci., 13 (1): 26-34, DOI: 10.15740/HAS/IJPS/13.1/26-34.

Article chronicle : Received : 17.08.2017; Revised : 09.11.2017; Accepted : 23.11.2017

\section{$\longrightarrow$ MEMBERS OF THE RESEARCH FORUM}

Author to be contacted :

M. Lakshmi Naga Nandini, Department of Plant Pathology, College of Horticulture, Dr. Y.S.R. Horticultural University, Anantharajupeta (A.P.) India

Email : mssp11554@gmail.com

Address of the Co-authors:

C.H. Ruth, Department of Plant Pathology, College of Horticulture, Dr. Y.S.R. Horticultural University, Anantharajupeta (A.P.) India

K. Gopal, Department of Plant Pathology, Dr. Y.S.R. Horticultural University, Venkataramannagudem (A.P.) India 